\title{
Blast and Fragmentation Studies of a Scaled Down Artillery Shell-Simulation and Experimental Approaches
}

\author{
K Ahmed*, A Q Malik, A Hussain, I R Ahmad, I Ahmad \\ School of Chemical \& Materials Engineering (SCME) \\ National University of Sciences and Technology, Islamabad \\ Pakistan, PC 44000
}

\begin{abstract}
Blast and fragmentation of a scaled down model of standard artillery shell is investigated experimentally and numerically. Simple experimental techniques are employed in this study to measure the fragments' velocity, mass and spatial distribution. Fragments of mass ranging from tens of milligram(s) to 6.4 grams are produced with velocities ranging from 960 to $1555 \mathrm{~m} / \mathrm{s}$. The cylindrical part of the shell has larger contribution among high velocity fragments $\sim 1369-1555 \mathrm{~m} / \mathrm{s}$ than the conical and rear parts due to higher charge to mass (C/M) ratio. Overpressure of 44.2psi (304.7kPa) is measured at stand-off distance of $0.550 \mathrm{~m}$. The numerical simulation of fragmentation is carried out using Smoothed Particle Hydrodynamics (SPH) solver available in ANSYS AUTODYN. A coupled Euler-ALE (Arbitrary Lagrangian-Eulerian) approach is used to simulate the shell blast propagation in the surrounding air. A good agreement is achieved between the simulation and experimental results. The investigation can help in the development of protective configurations against the damaging effects of blast and fragmentation.
\end{abstract}

\section{INTRODUCTION}

Fragmentation is the breakage of shell body into a number of pieces. It is a complex phenomenon where the fragmenting material fractures under intense shock wave loading produced by the detonation of high explosive. Once the metal casing starts to break, the highly pressurized product gases escape out of confinement, resulting in the formation of a blast wave [1]. The blast wave propagates outwards and leads the fragments. The neighboring objects are first hit by this blast wave followed by the high velocity fragments causing severe damage. The study of the fragmentation phenomenon is important for design, safety and efficiency analysis of ammunition, as well as to devise protective measures against the damaging effects $[1,2]$. The fragment velocity, shape and mass distribution support in completing the characterization of the fragmentation process [1]. Mott [3], presented relationship for fragment distribution as given in equation (1);

*Corresponding Author: Khurshid.phd@scme.nust.edu.pk 


$$
N \sim\left(1-e^{\left(\frac{m}{m_{r e f}}\right)^{\beta}}\right)
$$

Where $N$ is the cumulative number of fragments and $m$ is the fragment mass. Gurney [4] proposed a relation for estimating fragment velocity for cylindrical casing exploded under energetic material filling. The relation for velocity is given in equation (2)

$$
V=\sqrt{2 E} \sqrt{\frac{\frac{C}{M}}{1+0.5 \frac{C}{M}}}
$$

Where $M$ and $C$ are metal and energetic material mass/unit length, and $\sqrt{2 E}$ is the Gurney constant for the energetic material in $\mathrm{km} / \mathrm{s}$. The Gurney constant can also be approximated by a simple expression [5] as given in equation (3)

$$
\sqrt{2 E}=0.338 D
$$

Where, $D$ is velocity of detonation. Huang et al [6] proposed a relationship for initial fragment velocity calculation along the axis of cylindrical casing by including the influence of end effects. The relation is shown in equation (4);

$$
V=\left(1-0.361 e^{1.111 x / d}\right) \cdot\left(1-0.192 e^{3.03(L-x) / d}\right) \cdot \sqrt{2 E} \sqrt{\frac{\frac{C}{M}}{1+0.5 \frac{C}{M}}}
$$

In equation (4) $\mathrm{x}$ represents the distance to the detonation end along the axis of cylindrical casing, $d$ is the diameter of energetic material, and $L$ is the casing length.

Several researchers have presented their work on fragmentation phenomenon but very few have focused on a complete characterization. Prytz, A. K. and G. Odegardstuen [7] investigated the fragmentation of a $155 \mathrm{~mm}$ artillery shell by statically detonating the shell and recovering its fragments to analyze the mass distribution. Fragments' velocities were estimated with numerical simulation only. Mohammad A. Abdallah [8] conducted fragmentation analysis of OG-7 warhead using AUTODYN and compared the results with pit test results for OG-7 warhead. Discrepancy in mass distribution with tested data was observed. Marriot et al [9] studied computer modelling of small fragmenting warheads and reinforced for employment of a 3D hydro codes for better prediction of mass and velocity distribution. Anderson et al [10] employed a time-dependent 2D finite-difference code to model the fragmenting cylinders. Ma et al [11] conducted numerical and experimental investigations into the fragment spatial distribution of a prismatic casing under internal explosive loading. The fragment velocity was not measured. Gold, V. M [12] developed a new multi-region model for large L/D explosive fragmentation warheads that reproduced the experimental data on fragmentation reasonably well. 
Kong Xiangshao et al [1] numerically investigated explosive fragmentation of metal casing using SPH method. Arnold et al [13] studied the fragmentation behavior of very light and heavier casings. Nystrom and Gylltoft [14] investigated the combined effects of blast and fragmentation loading on reinforced concrete and concluded that the combined effects of blast and fragmentation loading are more severe than their separate effects. Rasico, J. C. Newman, et al [15] simulated the blast and fragmentation of HE (high explosive) filled, M795 artillery shell IED (improvised explosive device) buried in soil. The fragments impacted on vehicle hull were investigated numerically. Jing Q. and T. Zhou [16] investigated the effects of different grooved surfaces on fragment distribution pattern of a warhead. Zecevic et al [5] compared the fragmentation pattern and effectiveness of M54 projectile with M107 and concluded that body material and energetic filling plays important role in fragmentation mass and velocity distribution. Ugrčić [17] performed numerical simulation of the fragmentation process by varying the mechanical properties of the casing and type of explosive filling using coupled Euler-Lagrange method. Cullis et al [18] utilized Eulerian approach with experimental work on natural fragmentation of an explosively loaded steel cylinder. Moxnes et al [19] studied the fracture behavior of the cylindrical steel casing experimentally and numerically. An, X. et al [20] investigated the effects of the diameter of the hollow core on the fragment velocities of warheads under asymmetrical initiation. Tanapornraweekit et al [21] presented an approach to determine lethal ranges for fragmentation warheads with and without preformed fragments. The lethal radius is evaluated based on velocity of natural and preformed fragments and the total number and average natural fragment mass. Techniques like flash radiography and high speed photography have been cited in literature for measuring fragment velocity. These are highly accurate and precise diagnostic techniques. However, these are very expensive and mostly unavailable at the majority of relevant research institutes. Accordingly, simple experimental arrangement is proposed in this study to measure fragment velocity, besides measuring the fragment's mass and spatial distribution.

Fragmentation is the most lethal among the explosive detonation effects because fragments can move to large distances and cause serious injuries to humans let alone the soft targets [22]. The experimental testing of combined blast and fragmentation of munition as well as IEDs requires enormous expenses. The present work deals with the experimental and numerical investigation of blast and fragmentation of a geometrically scaled down artillery shell in an open-air environment. Besides measuring the fragment's mass and spatial distribution, the work also focused on measuring fragment velocity by employing simple experimental approaches. The blast wave parameters for shell are also determined with pressure transducers. SPH solver available in ANSYS AUTODYN is used to study fragmentation of metallic casing under explosive loading. A coupled Euler-ALE approach is used to simulate the blast effects produced by the shell detonation. 


\section{EXPERIMENTAL WORK}

The detonation of an explosive device results in the production of a blast wave in air. When this charge is encased, the detonation energy and momentum are partitioned into formation of fragments and the blast wave. Usually the blast wave leads the initial fragmentation in a nearfield explosion, however, the fragments move with a high velocity and can cover large distances. Both these effects cause severe damage to surrounding objects. To investigate both of these effects, a standard artillery shell is considered. The field testing and required data acquisition of this standard shell is a difficult task and requires significant resources. Therefore, a geometrically scaled down ( 1/4th) model of this shell is selected to investigate the blast and fragmentation effects to its surrounding. The shell as shown in Fig. 1 comprised a hollow steel casing filled with Comp-B explosive. The Comp-B filling is illustrated in the cut-view of this figure. A standard $155 \mathrm{~mm}$ shell is also shown in Fig. 1(d). The parameters of a standard $155 \mathrm{~mm}$ shell and scaled down shell are presented in Table 1.

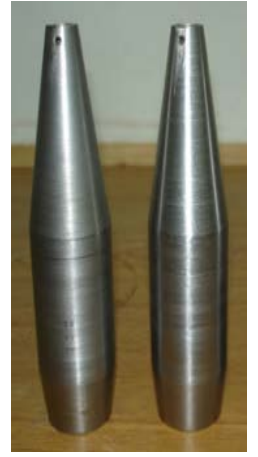

(a)

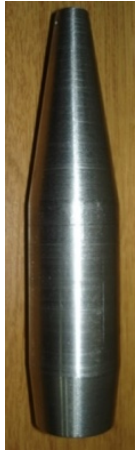

(b)

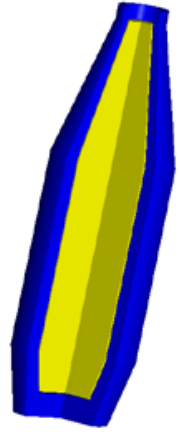

(C)

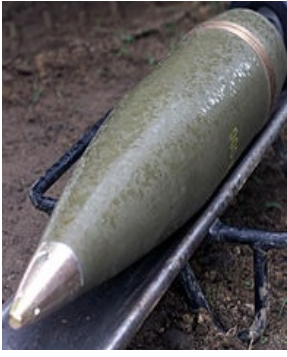

(d)

Figure 1: (a, b) Scaled down shell (c) its cut-view and (d) standard 155mm shell

Table 1: Material and dimensions of standard 155mm and scaled down shell

\begin{tabular}{llllll}
\hline & & Mass (g) & Length(mm) & Cyl. OD(mm) & ID (mm) \\
\hline Scaled shell & Steel casing & 450 & 140 & 37 & 28 \\
& Comp-B & 104 & 127 & 28 & -- \\
Standard & Steel casing & 35700 & 630 & 154 & 132 \\
155mm Shell & Comp-B & 6800 & 535 & 133 & -- \\
\hline
\end{tabular}

Three experiments were conducted with this scaled down model to study the blast and fragmentation effects. PIEZOTRON 211B series pressure transducers were used with Data Acquisition (DAQ) system to measure peak overpressure (Ps) and arrival time (Ta) of the blast wave at different distances [23] from the shell center. The experimental layout is shown in Fig. 2. 


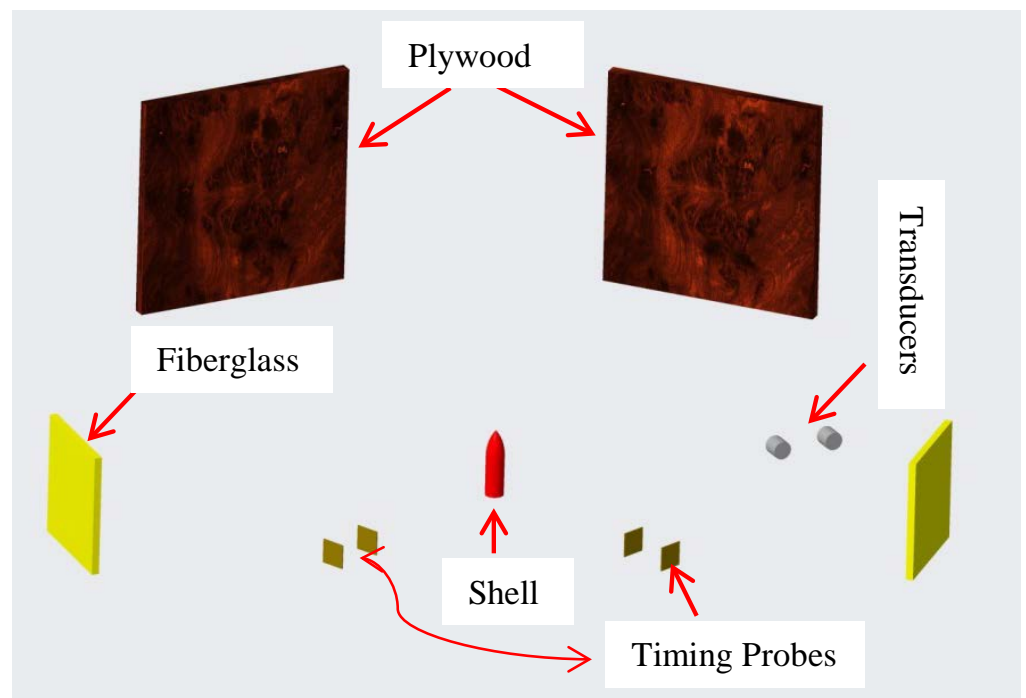

Figure 2: Layout for blast and fragmentation tests

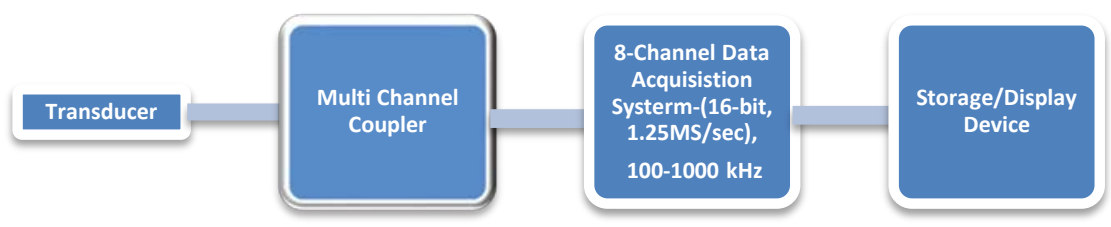

Figure 3: Components for Blat parameters acquisition

Positive impulse is computed by integrating the pressure-time plot for positive phase duration. Two pressure transducers were used to measure side-on pressure for each test as shown in Fig. 4. Transducers were sealed in steel pipe while wooden blocks and sandbags were also employed for protection against high velocity fragments of the shell. The setup is shown in Fig. 4(b \& c). The measured peak pressure plots for second and third tests are shown in Fig. 5. The peak overpressure is plotted in PSI (pounds per square inches) for easy understanding of the readers. 

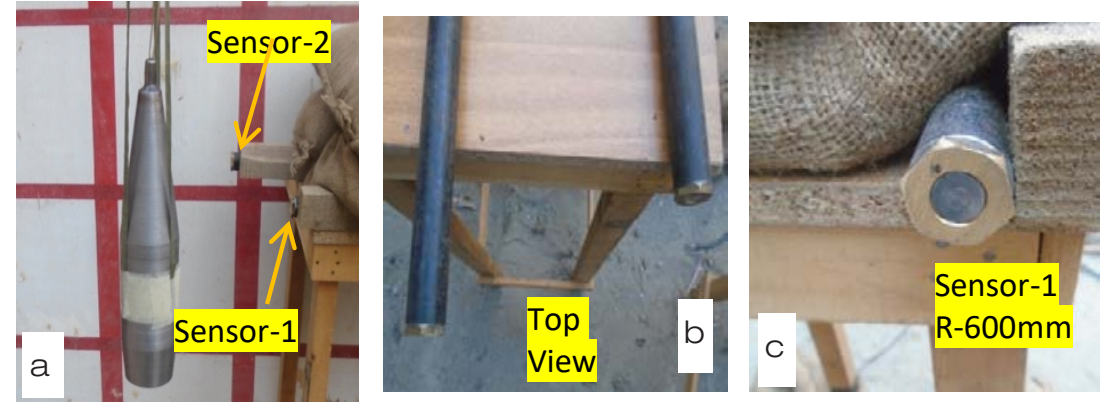

Figure 4: Setup for measuring (a) peak pressure and (b, c) close view of transducers with protection
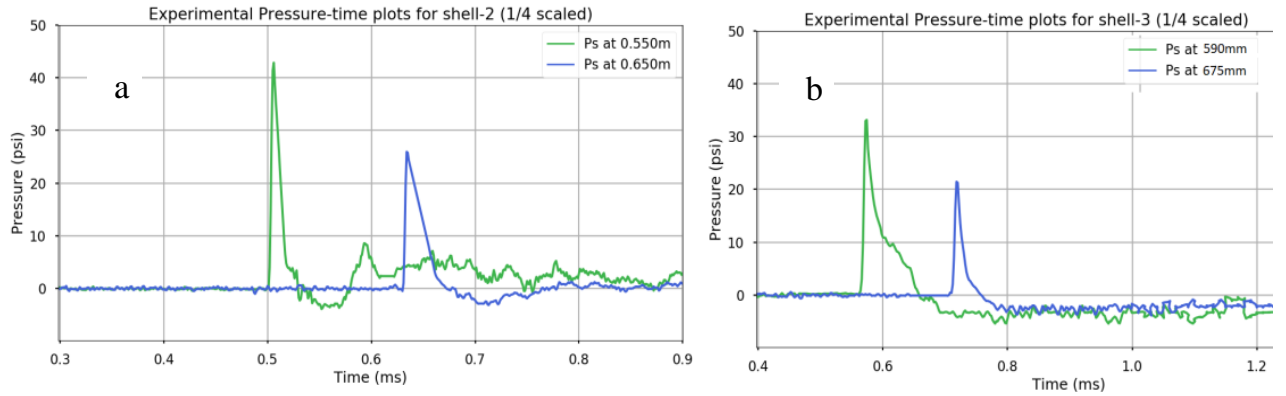

Figure 5: Peak pressure plots at (a) $0.55 m \& 0.65 m$ (b) $0.59 m$ \& $0.675 m$

Flat Brass timing probes shown in Fig. 6 were used to measure the fragment's arrival time and velocity at predefined distances. The probe comprised two Brass foils, measuring $125 \mathrm{x}$ $125 \mathrm{~mm}^{2}$ with thickness of $0.1 \mathrm{~mm}$, separated by a $0.1 \mathrm{~mm}$ thick Mylar sheet. The Mylar sheet has enough strength to provide sufficient insulation. A cable is used to connect the two Brass foils with a recording device like an oscilloscope or a transient recorder. A magnified section view is shown in Fig. 6(c). Upon impact and penetration by a metallic fragment the electrical path is completed momentarily and the event is registered by a recording device. Two such probes when placed in parallel and separated at a fixed distance $(\Delta S)$ as shown in Fig. 6(d) can record the fragment's impact time. The fragment's velocity is computed with the help of the measured time interval and known separated distance. The probes are fixed rigidly to avoid any disturbance by the approaching blast wave.

Fragment velocities from different locations of the shell are measured using these timing probes. The brass probes placed just below the shell base are also used to find the number of fragments from this part of the shell. The setup is shown in Fig. 7. 

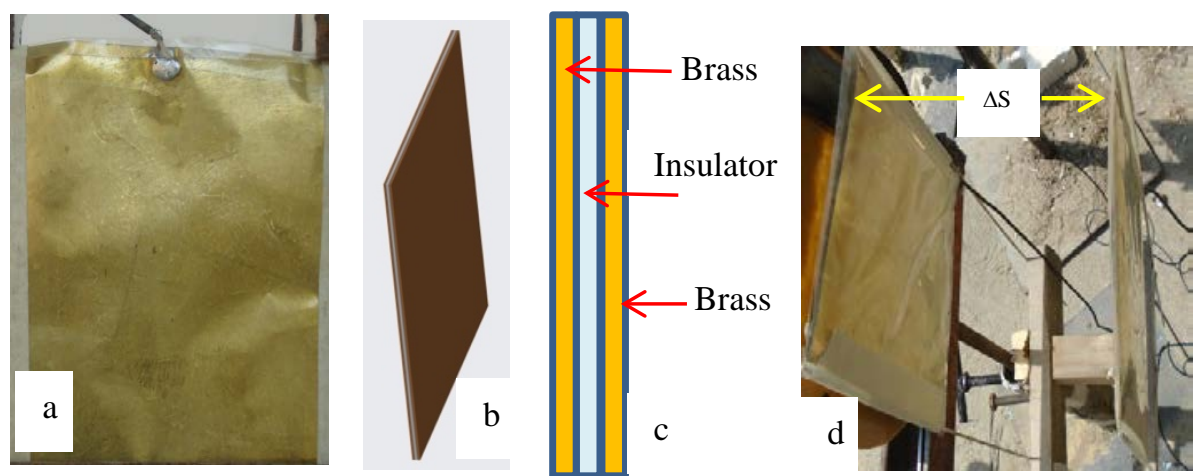

Figure 6: (a) Flat Brass probe (b) 3-D view(c) section view (d) Two probes setup

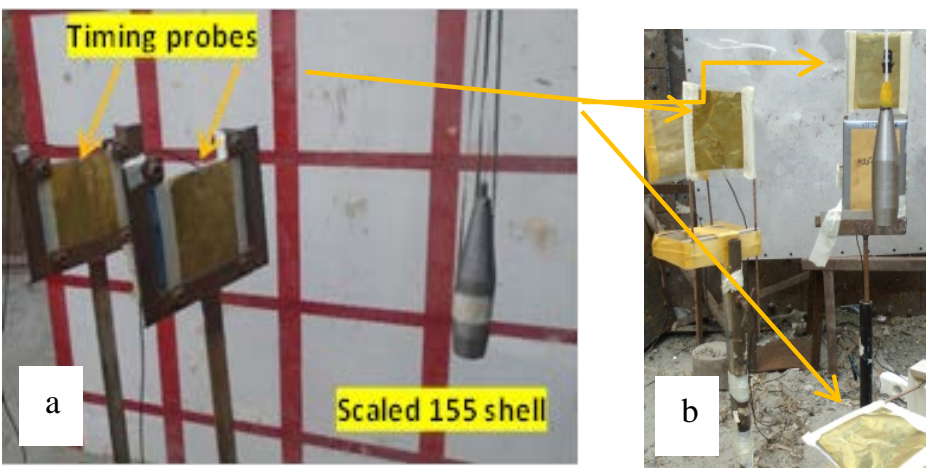

Figure 7: Flat probes arrangement for fragment velocity measurement

The destructive potential of the fragments is a function of their kinetic energy distribution. Therefore, the initial velocity and mass distribution of the fragments need to be determined [22]. The fragment spatial distribution was determined with the help of holes in fiberglass and plywood witness plates perforated by the fragment impact. Two fiberglass sheets measuring $457 \times 457 \mathrm{~mm}^{2}$ and spanning $25.8^{\circ}$ both in azimuth and in elevation were placed one meter apart from the center of the scaled shell for Test 1 . The thickness of these sheets was $10 \mathrm{~mm}$. The testing setup is shown in Fig. 8(a). For the other two experiments, plywood sheets measuring $600 \times 600 \times 8 m^{3}$ as shown in Fig. 8(b) is placed at $700 \mathrm{~mm}$ from the shell. The plywood sheets spanned $46^{\circ}$ in azimuth and $44^{\circ}$ in elevation. A layout of the experimental setup is shown in Fig. 9.

The impact and perforation of fragments through fiberglass and plywood witness sheets, as shown in Figs. 10 and 11, were used for estimating the total number of fragments produced and their spatial distribution.

The majority of the fragments, especially small ones, could not be recovered. A few of the recovered fragments are shown in Fig. 12. The fragments' mass, size and velocity distribution is presented in the results and discussion section. 

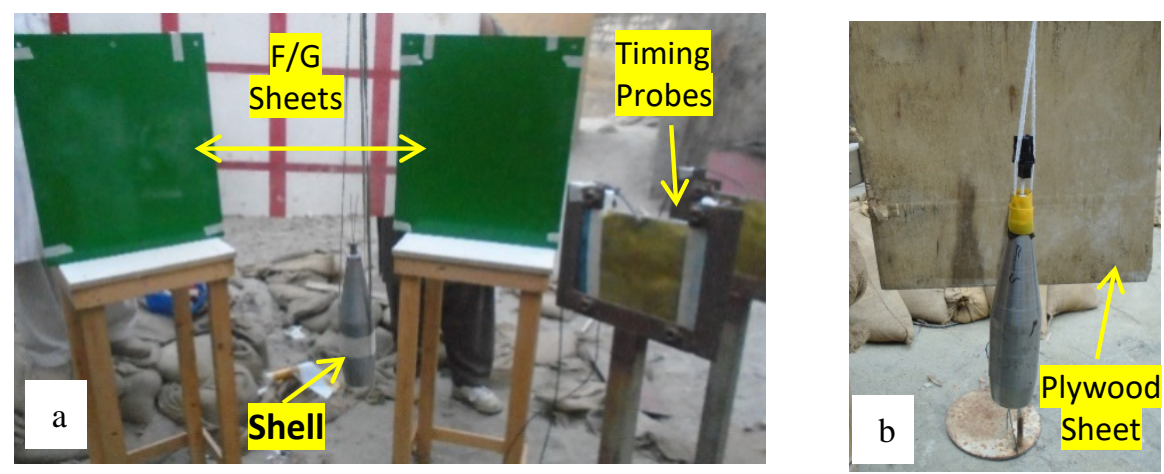

Figure 8: Testing setup with (a) fiberglass ( $F / G$ ) sheets and timing probes (b) plywood sheet

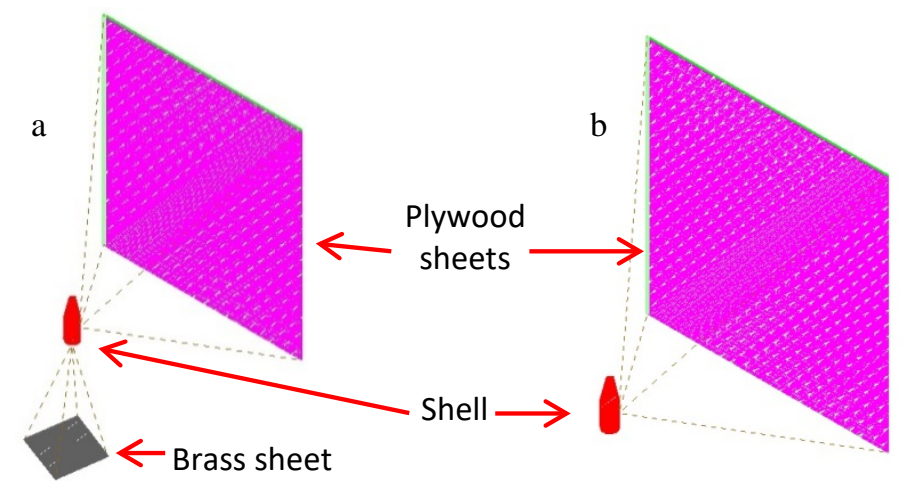

Figure 9: Setup for fragments impact and spatial distribution (a) Test-2 and (b) Test-3
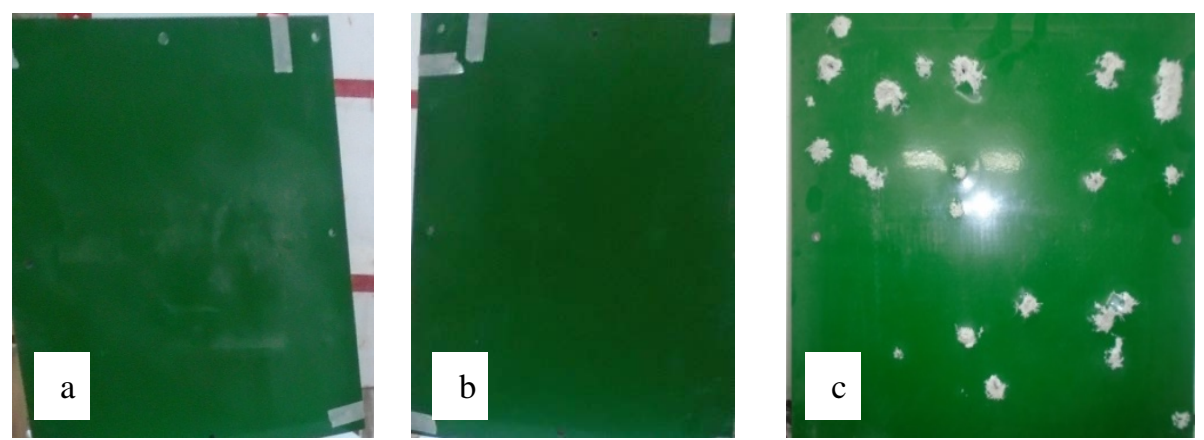

Figure 10: Fiberglass witness sheets $(a, b)$ before and (c) after fragments impacts 

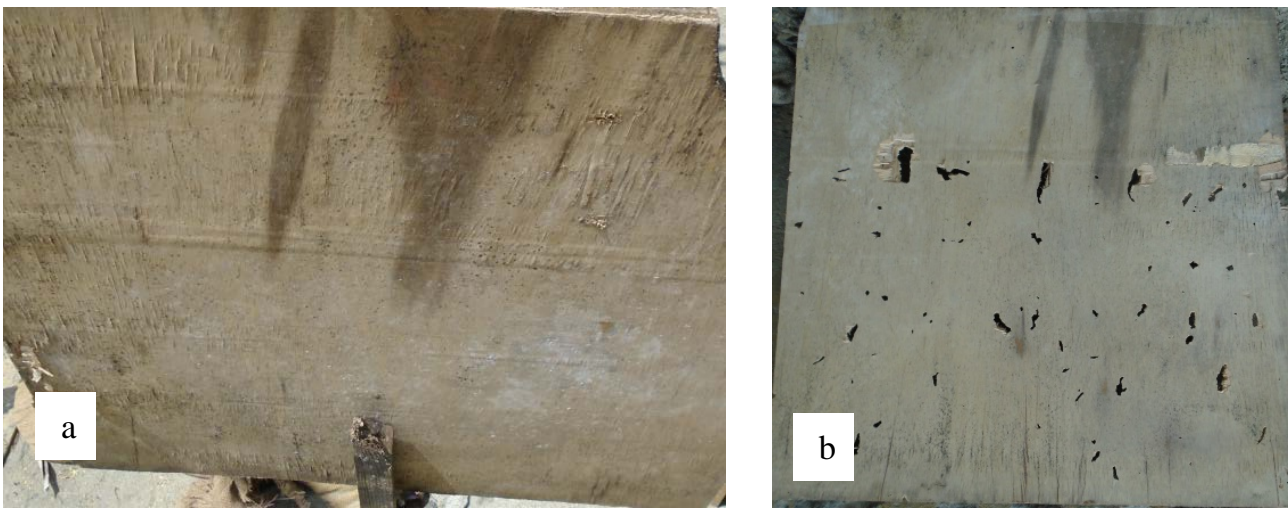

Figure 11: Plywood witness sheets (a) before and (b) after the fragments impact
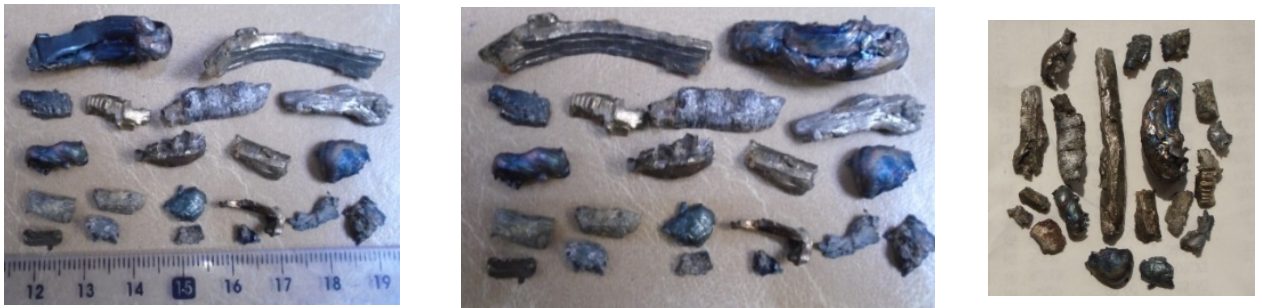

Figure 12: Fragments recovered in the tests

\section{NUMERICAL MODELING AND SIMULATION}

ANSYS AUTODYN [24] is used to develop a numerical model and simulate the fragmentation phenomenon. Smoothed Particle Hydrodynamics (SPH) solver available in this non-linear dynamics software is used to simulate explosively driven fragmentation. SPH being a meshfree method can handle nonlinear problems with large deformation without mesh degeneration or tangling, contrary to the Lagrange solver. Therefore, a non-physical, numerical erosion model is not required [8]. Euler Multi-Material (MM) solver coupled with ALE is used to simulate the blast phenomenon of the exploded shell in air.

\subsection{Material Modeling}

JWL (Jones-Wilkins-Lee) [25] equation of state (EoS) is used for expansion of Comp-B product gases. The JWL EoS is given in equation (5).

$$
P=A\left(1-\frac{\omega}{R_{1} V}\right) e^{-R_{1} V}+B\left(1-\frac{\omega}{R_{2} V}\right) e^{-R_{2} V}+\frac{\omega E}{V}
$$


Where $E$ is the detonation energy per unit volume, $V$ is the ratio of the detonation product volume with the original volume of the explosive, and $A, B, R 1, R 2$ and $\omega$ are empirical fitting parameters. Ideal gas EoS shown in equation (6) is used for air surrounding the shell.

$$
P=\rho_{a}(\gamma-1) e
$$

Where $P$ is the pressure, $\gamma$ specific heats ratio ( $\gamma=1.4$ for air), e is specific internal energy and $\rho_{a}$ is air density. The JWL parameters for Comp-B and ideal gas parameters for air are presented in Table 2.

Table 2: EoS and parameters for Comp-B and air

\begin{tabular}{llll}
\hline \multicolumn{2}{c}{ JWL parameters for Comp-B } & Air & \\
\hline Equation of State & JWL & EOS & Ideal gas \\
Ref. density $(\mathrm{g} / \mathrm{cm} 3)$ & 1.717 & Density $\left(\mathrm{g} / \mathrm{cm}^{3}\right)$ & 0.00123 \\
Parameter A & $5.2430 \mathrm{E}+08(\mathrm{kPa})$ & $\gamma$ & 1.4 \\
Parameter B & $7.67800 \mathrm{E}+06(\mathrm{kPa})$ & $\mathrm{e}$ & $2.068 \mathrm{e} 5 \mathrm{~kJ} / \mathrm{kg}$ \\
Parameter R1 & 4.200 & & \\
Parameter R2 & 1.1 & & \\
Parameter $\omega$ & $3.40000 \mathrm{E}-01$ & & \\
C-J Detonation velocity & $7.980 \mathrm{E}+03(\mathrm{~m} / \mathrm{s})$ & & \\
C-J Energy/unit volume & $8.50 \mathrm{E}+06\left(\mathrm{~kJ} / \mathrm{m}^{3}\right)$ & & \\
C-J Pressure & $2.950 \mathrm{E}+07(\mathrm{kPa})$ & & \\
\hline
\end{tabular}

Steel AISI-1006 is used as casing material. The Shock EoS (Mie-Grüneisen form) [26] is used as the equation of state model for Steel-1006. This EOS as shown in equation (7) is widely used for materials under shock loading.

$$
P=P_{H}+\Gamma \rho\left(E-E_{H}\right)
$$

The Johnson-Cook strength model [27] is used to simulate the behavior of the steel (AISI1006) shell under high strain rate loading of explosive detonation. The model presented in equation (8) reproduced the strain hardening, strain rate and thermal softening effects of steel casing subjected to such high strain rate loading very well.

$$
\sigma_{y}=\left[A+B \varepsilon_{p}^{n}\right]\left[1+C \ln \varepsilon_{p}^{*}\right]\left[1-T_{H}^{m}\right]
$$

Where $A, B, C, n$ and $m$ are constants for each material and $\mathrm{T}_{\mathrm{H}}$ is homologous temperature. The material model parameters for steel, Comp-B and air are used from ANSYS AUTODYN library. The Johnson-Cook failure model [28] shown in equation (9) is used along with the strength model for casing material (AISI-1006). 


$$
\varepsilon_{f}=\left[D_{1}+D_{2} e^{D_{3} \sigma^{*}}\right]\left[1+D_{4} \ln \left|\varepsilon^{*}\right|\right]\left[1+D_{5} T_{H}\right]
$$

The values of constants D1 to D5 for steel 1006 are presented in Table 3.

Table 3: Johnson Cook damage parameters for Steel-1006 [29]

\begin{tabular}{ccccc}
\hline D1 & D2 & D3 & D4 & D5 \\
\hline-0.8 & 2.1 & 0.5 & 0.0002 & 0.61 \\
\hline
\end{tabular}

\subsection{Fragmentation}

Fragmentation modelling has grown significantly with increasingly realistic predictions [29]. SPH solver in ANSYS AUTODYN is used to model the scaled down shell for fragmentation studies. As the computational grid influences the accuracy and reliability of the numerical prediction results [30]. A particle size of 1 is used for packing after optimizing the size for SPH solver [2, 23]. Quarter symmetry of the shell is modeled with 28820 nodal points to reduce the computational time. The shell model and gauge points defined on steel casing are shown in Fig. 13.
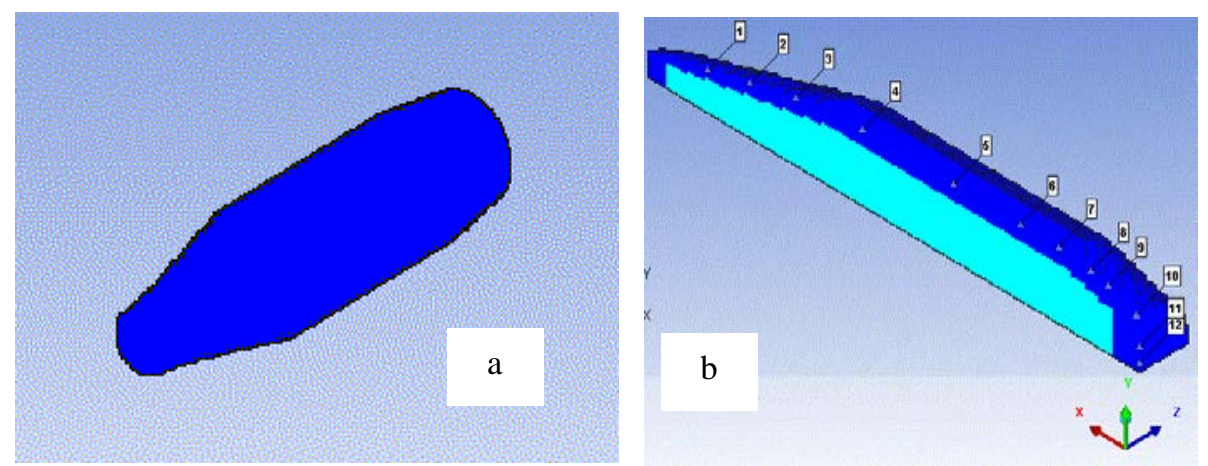

Figure 13: (a) SPH Model of scaled down shell (b) gauge point's location on casing

ANSYS AUTODYN has the capability to generate fragment analysis under material status plot size. When fragmentation option is checked, it can output fragment analysis in HTML format. The analysis comprised number of fragments, mass, kinetic energy, momentum, length, origin, coordinates and velocity of each fragment. The fragmentation of shell casing at different time and the venting of pressurized detonation product gasses are shown in Figs. 14 and 15. The escape of product gases leads to the formation of the blast wave which surpasses the fragments.

The number of fragments and their mass distribution is schematized in Fig. 16. Fragments with mass ranging from tens of milligrams to a few grams are produced. The fragments' velocity profile is shown in Fig. 17. The fragment mass distribution and velocity are important to evaluate the hit density and lethal radius calculations [21]. 


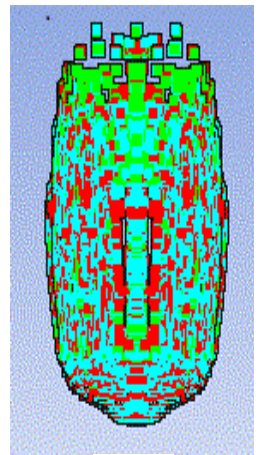

a

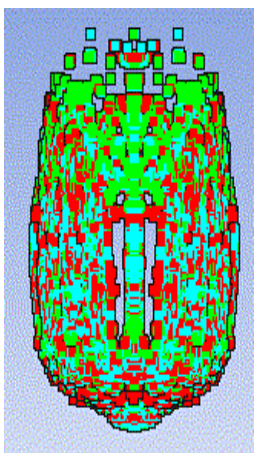

b

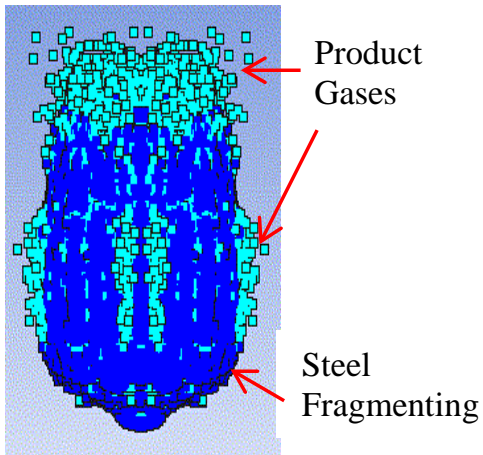

C

Figure 14: Fragmentation process (a) at $27 \mu \mathrm{s}$ (b) at $48 \mu \mathrm{s}$ and (c) venting of product gases- $48 \mu \mathrm{s}$

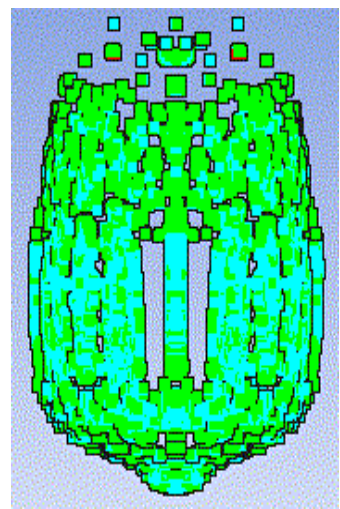

a

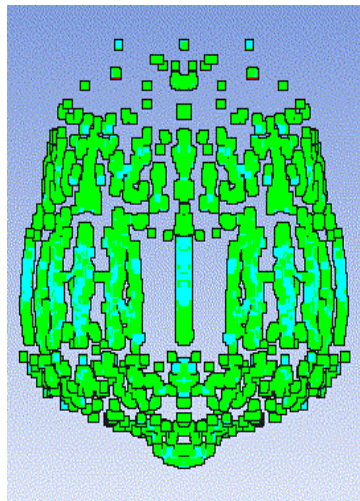

b

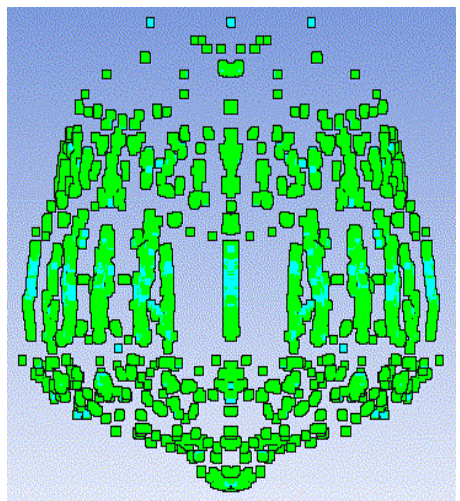

C

Figure 15: Fragmentation process (a) at $57 \mu \mathrm{s}(\mathrm{b})$ at $90 \mu \mathrm{s}$ and (c) $123 \mu \mathrm{s}$

The velocity distribution with the number of fragments is shown in Fig. 18. The majority of the fragments exhibit velocities ranging between $1000 \mathrm{~m} / \mathrm{s}$ to $1400 \mathrm{~m} / \mathrm{s}$. Only a few fragments have velocities below $800 \mathrm{~m} / \mathrm{s}$. 


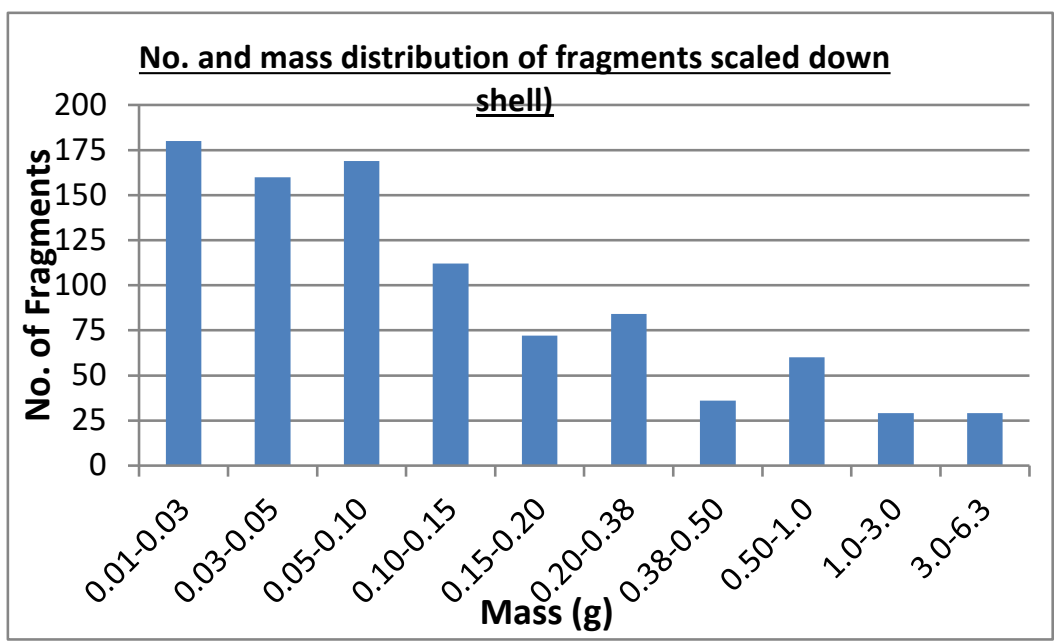

Figure 16: Number of fragments and mass distribution
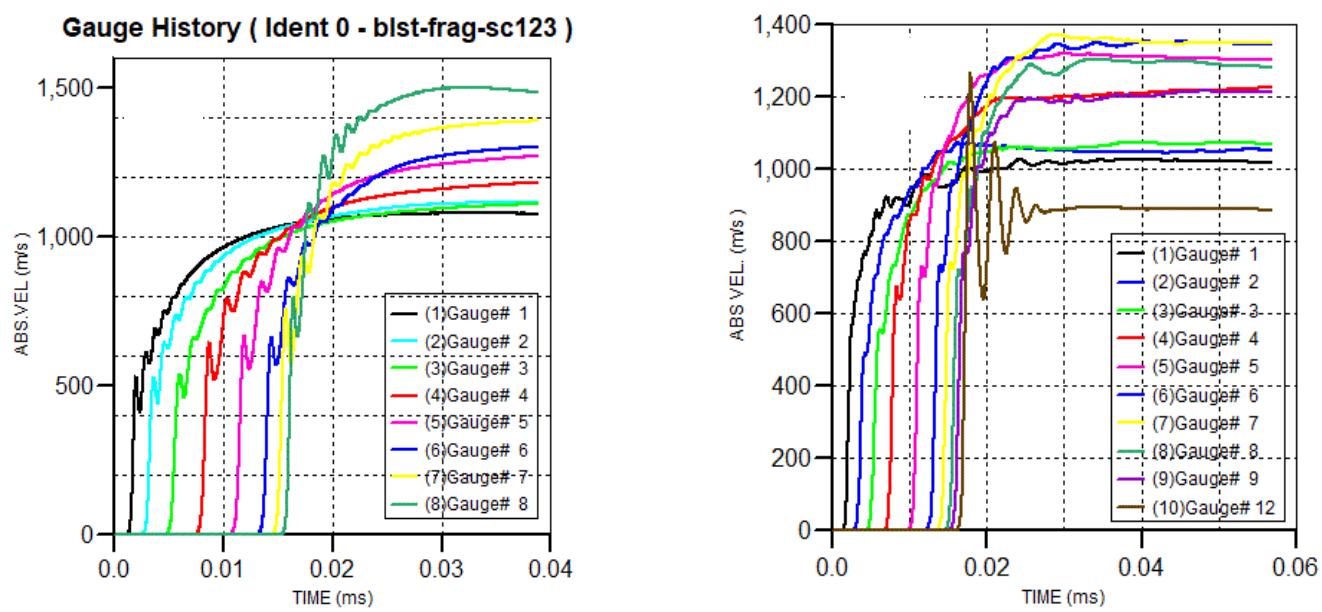

Figure 17: Fragment velocities of gauge points defined on shell casing (a) with ALE solver (b) with SPH 


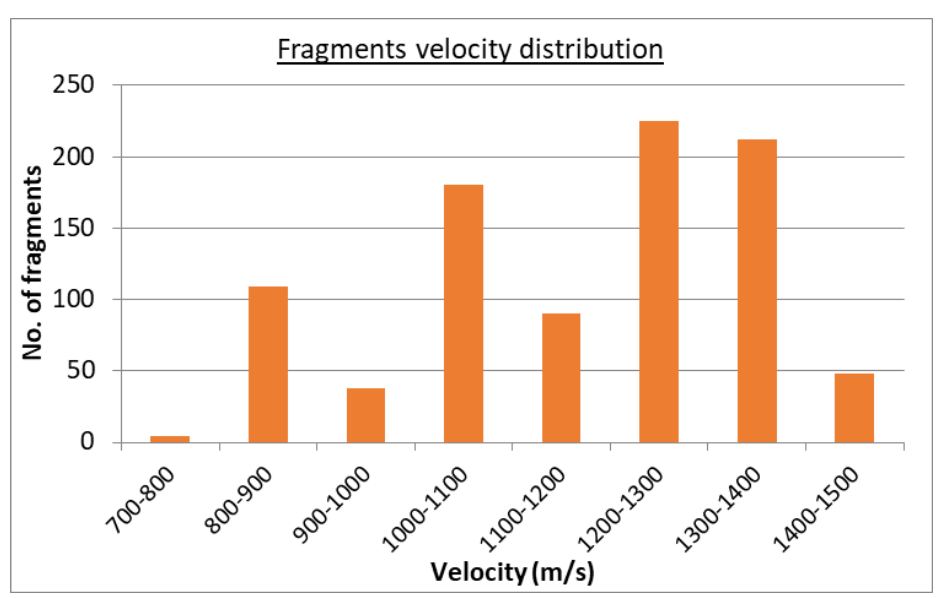

Figure 18: Number of fragments and their velocity distribution

\subsection{Blast Parameters}

Simulation for blast parameters is performed using coupled ALE-Euler Multi-Material (MM) approach in ANSYS AUTODYN. The hollow steel shell is modeled in ALE whereas Comp$B$ filling and surrounding air are modelled in Euler MM solver. The ALE mesh is embedded inside the Euler MM fixed mesh. The interaction between the two solvers is controlled by an automatic coupling option available in ANSYS AUTODYN. An optimized grid size of $1 \mathrm{x} 1$ $\mathrm{mm}^{2}$ is used for both solvers [2, 23]. The air surrounding the shell is filled for ambient pressure of $101 \mathrm{kPa}(14.7 \mathrm{psi})$ by assigning specific internal energy of $2.068 \mathrm{e}+5 \mathrm{~kJ} / \mathrm{kg}$. Flow out boundary condition is used at the Euler sub-grid boundaries. The numerical model of the shell, detonation propagation and expansion are shown in Fig. 19. The Comp-B filling is completely detonated in $15.8 \mu \mathrm{s}$.

The expansion and fracturing of the casing material lead to initial escape of product gases and the subsequent formation of a blast wave in air. The venting of product gasses at $40 \mu \mathrm{s}$, subsequent blast wave formation and its propagation in surrounding air is depicted in Fig. 20. The radial propagation of blast wave with time is shown in Fig. 21.

The pressure-time history at gauge points is integrated for positive phase duration to obtain positive impulse. The peak incident pressure and positive impulse at distances of $0.60 \mathrm{~m}$ and $0.760 \mathrm{~m}$ for simulated and experimental results are shown in Fig. 22. The blast arrival time and peak pressure values are in close agreement with the experimental findings. However, a discrepancy in impulse is observed at $0.60 \mathrm{~m}$. 


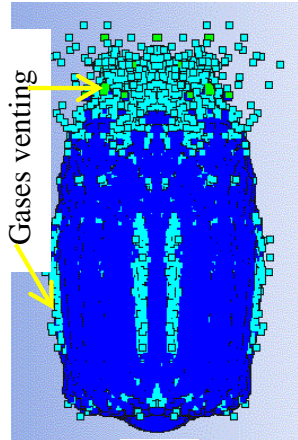

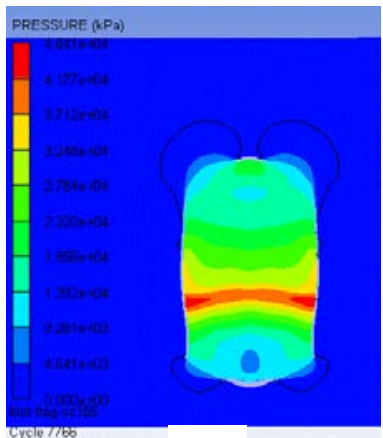

b

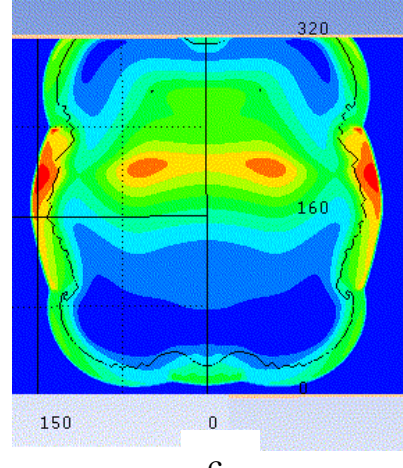

C

Figure 20: (a) Venting of pressurized gases in air at $\mathrm{t}=40 \mu \mathrm{s}$ and expansion (b) at $\mathrm{t}=61 \mu \mathrm{s}(\mathrm{c})$ at $90 \mathrm{~s}$
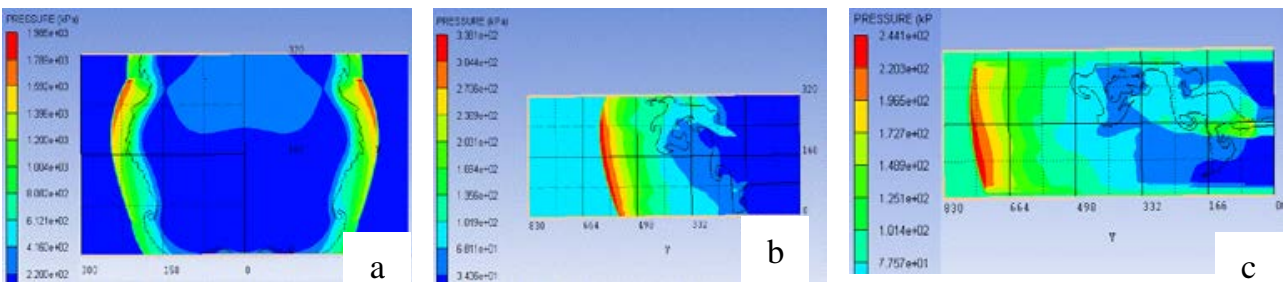

Figure 21: (a) Blast wave propagation in air at $t=0.150 \mathrm{~ms}$, (b) at $\mathrm{t}=0.604 \mathrm{~ms}$ and (c) at $\mathrm{t}=0.88 \mathrm{~ms}$
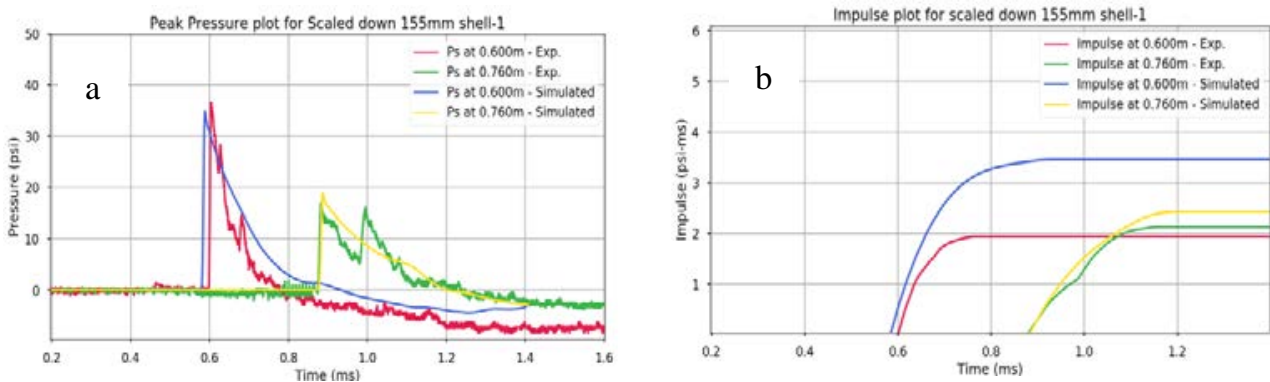

Figure 22: Simulated and experimental peak Pressure (a) and Impulse (b) plots for scaled down shell 


\section{RESULTS AND DISCUSSION}

Three tests are conducted with geometrically scaled down ( 1/4th) model of the $155 \mathrm{~mm}$ artillery shell to study the blast and fragmentation characteristics. An intense pressure is generated upon detonation of explosive filling in shell which is imparted to the metal casing within a time scale of microseconds. Consequently, the casing material started expanding until the shell body is fractured. The fragments thus produced start moving outwards under pressurized expanding gases, until these gases escape freely between the fragments. In due course, secondary fragmentation occurs under tensile fractures [31]. A simple experimental approach is employed to measure the fragments' velocity. The testing setup with the timing probe for fragments' velocity measurement is shown in Fig. 23(a, b). The fragments' impacts on the timing probe can also be witnessed in Fig. 23(c). The impact time (t1) of the fragment on front probe is registered by an oscilloscope and transient recorder. When the second probe (placed behind the front one) is perforated by this fragment, time (t2) is recorded. Fragment velocity is computed by dividing the spacing between the two probes $(\Delta S)$, as shown in Fig. 24(a), by the time interval $\Delta \mathrm{t}(\mathrm{t} 2 \mathrm{-t} 1)$. The fragment impact and arrival time at timing probes placed at 430mm and 710mm from shell center is shown in Fig. 24(b \& c).
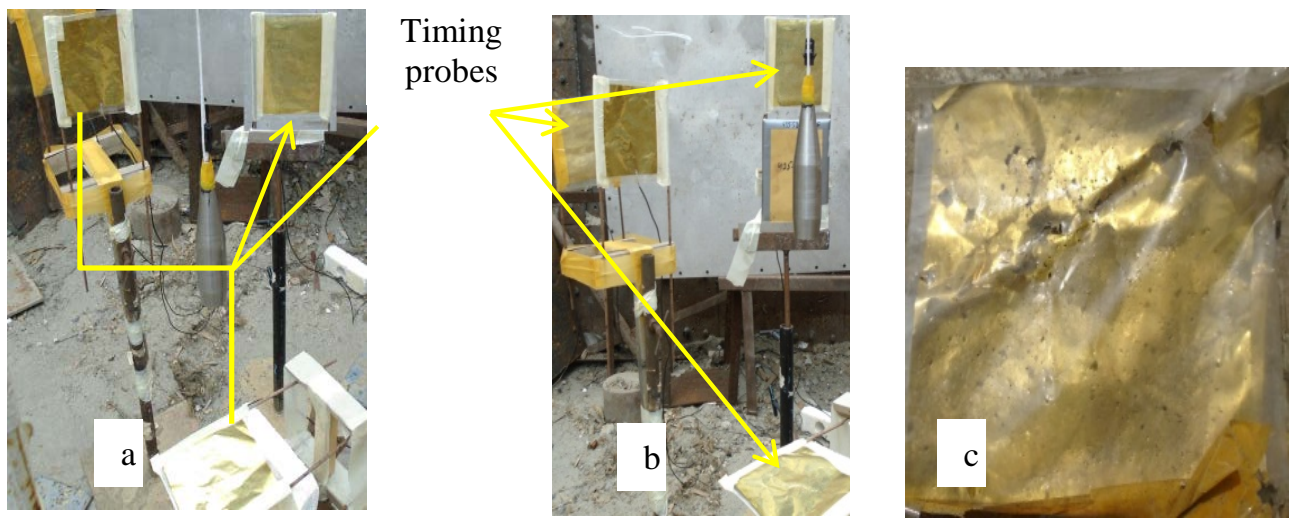

Figure 23: $(a, b)$ Fragment's velocity measurement from different parts of the shell (c) timing probe after fragment impact

The impact time of the fragments produced from different locations of the shell (base, cylindrical, conical etc.), as shown in Fig. 25, is recorded with the help of oscilloscope and transient recorder. The velocities are calculated from the known distances $(\Delta \mathrm{S})$ and recorded time intervals $(\Delta \mathrm{t})$. 


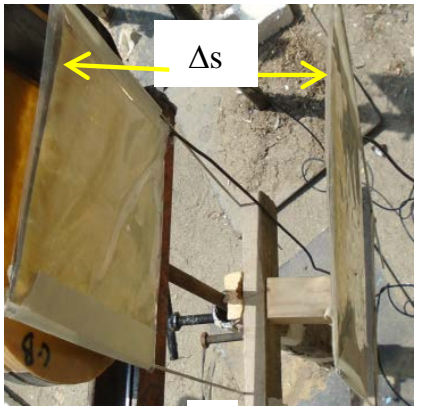

a

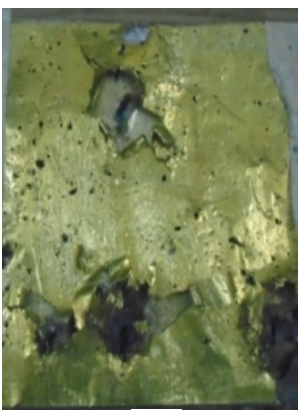

b

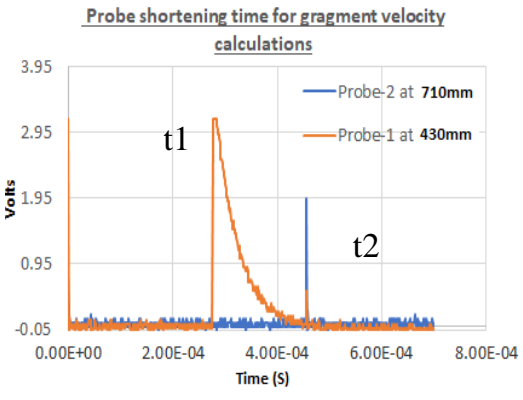

C

Figure 24: (a) Two probes setup (b) Fragment's impact on timing probe and (c) arrival time for velocity calculations

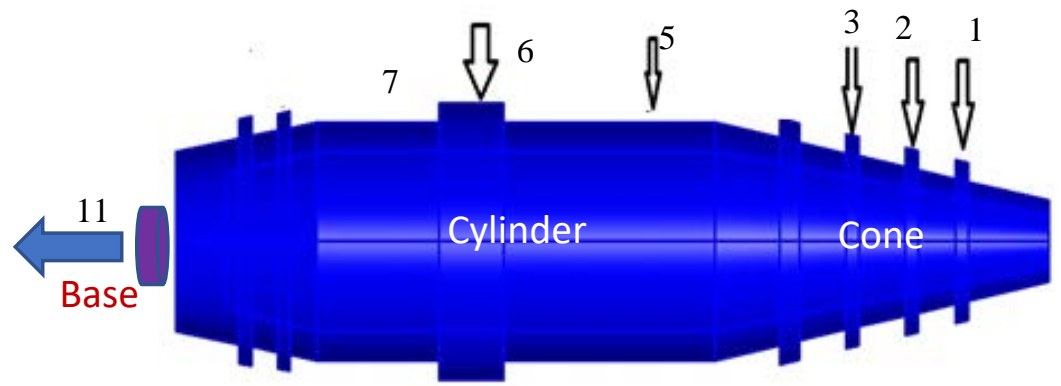

Figure 25: Fragment velocity calculated/measured at different positions of shell

Fragment velocities ranging from 960 to $1555 \mathrm{~m} / \mathrm{s}$ are measured for different locations of the shell. Fragments from the cylindrical portion of the shell are found flying with maximum velocities of 1346 to $1555 \mathrm{~m} / \mathrm{s}$ due to the highest C/M ratio. Fragments with relatively lesser velocities are produced from conical region on account of a smaller $\mathrm{C} / \mathrm{M}$ ratio. However, the minimum velocity of $960 \mathrm{~m} / \mathrm{s}$ is recorded for fragments produced from the base region of the shell as this was the thickest portion. The fragments from this part of the shell are most likely to be relatively massive, however, plenty of smaller probes have to be employed for this measurement. The fragment velocities are also computed from Gurney[4] relation (2.2) and Huang[6] modification (2.4). A comparison is presented in Table 4. The measured fragments velocities are found closer to Huang modified formulation; however, Gurney relation predictions are also in close agreement with other methods for the cylindrical part of the shell. The fragment velocities simulated by ANSYS AUTODYN are in close agreement with the experimentally measured values. A comparison of the fragment velocities determined analytically, numerically and experimentally is presented in Table 4. A possibility of measuring error in separation distances and its translation in fragments velocity is incorporated in tabulated results. 
Table 4: Comparison of experimental, numerical and analytical fragments velocities

\begin{tabular}{|c|c|c|c|c|c|c|c|c|c|c|}
\hline \multirow[t]{3}{*}{ Position } & \multicolumn{10}{|c|}{ Fragment velocity $(\mathrm{m} / \mathrm{s})$} \\
\hline & \multicolumn{7}{|c|}{ Frag. Velocities measured Experimentally } & \multicolumn{2}{|c|}{ AUTODYN Gurney } & \multirow{2}{*}{$\begin{array}{c}\text { Huang } \\
\text { m/s }\end{array}$} \\
\hline & $\begin{array}{c}\text { S1 } \\
\text { mm }\end{array}$ & $\begin{array}{c}\text { t1 } \\
\text { ms }\end{array}$ & $\begin{array}{c}\text { S2 } \\
\text { mm }\end{array}$ & $\begin{array}{c}\text { t2 } \\
\text { ms }\end{array}$ & $\begin{array}{c}\Delta \mathrm{S} \\
\mathbf{m m}\end{array}$ & $\begin{array}{c}\Delta \mathrm{t} \\
\mathrm{ms}\end{array}$ & $\begin{array}{c}\mathbf{V}=\Delta \mathrm{S} / \Delta \mathrm{t} \\
\mathbf{m} / \mathbf{s}\end{array}$ & $\mathbf{m} / \mathbf{s}$ & $\mathbf{m} / \mathbf{s}$ & \\
\hline Cylindrical & 430 & 0.276 & 710 & 0.456 & 280 & 0.180 & $1555 \pm 36$ & 1510 & 1340 & 1349 \\
\hline Cylindrical & 500 & 0.379 & 675 & 0.509 & 175 & 0.130 & $1346 \pm 29$ & 1350 & 1340 & 1349 \\
\hline Base & 370 & 0.307 & 550 & 0.484 & 170 & 0.177 & $960 \pm 28$ & 910 & -- & -- \\
\hline Conical & 500 & 0.5 & & -- & 500 & 0.520 & $961 \pm 19$ & 1025 & 1123 & 948 \\
\hline
\end{tabular}

Although flash radiography and high-speed photography techniques can measure highly accurate and precise fragment velocities, such facilities are mostly unavailable at the majority of research institutes and universities. The proposed method provides a fairly economical and simple approach to measure fragment velocities accurately.

The total number of fragments produced could not be collected as the fragments dispersed over a large area. Two fiberglass sheets each measuring 457 x $457 \mathrm{~mm}^{2}$ and spanning $25.8^{\circ}$ both in azimuth and in elevation, placed at a distance of $1.0 \mathrm{~m}$ from the shell, witnessed the fragments impact as shown in Fig. 26 for Test 1. Plywood sheets measuring 600 x 600 x $8 \mathrm{~mm}^{3}$ and spanning $46^{\circ}$ in azimuth and elevation are used to witness the fragments impact and perforation for the second and third experiments. Fragments weighing tens of milligrams to a maximum of $6.3 \mathrm{~g}$ are observed to impact the fiberglass/plywood sheets, as can be seen from Fig. 26. Most of the small-sized fragments could not be recovered. A few of the fragments recovered are shown in Fig. 12 of the experimental work section. The mass and size of recovered fragments are presented in Table 5. ANSYS AUTODYN results are also tabulated for the corresponding recovered fragments.
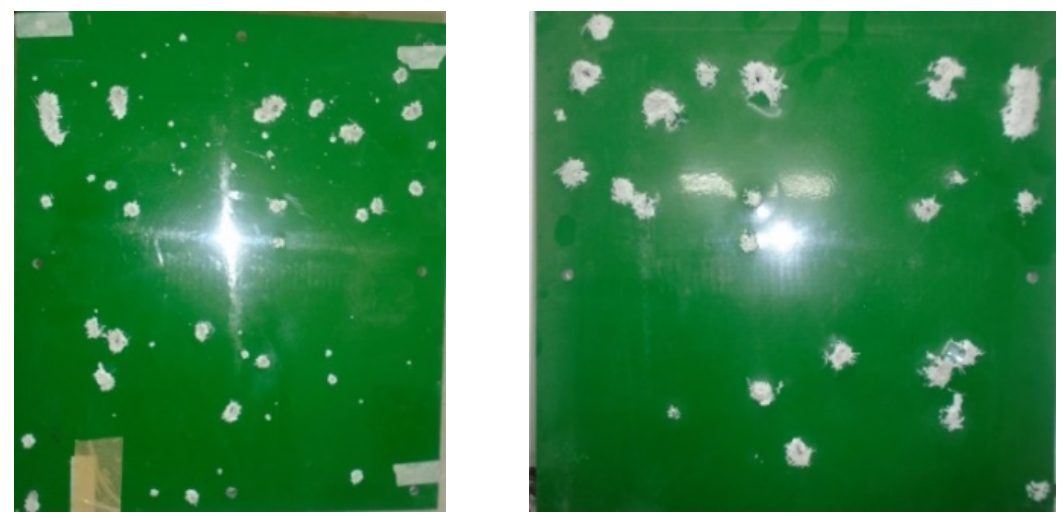

Figure 26: Fragments impacts and perforation through Fiberglass witness sheets 

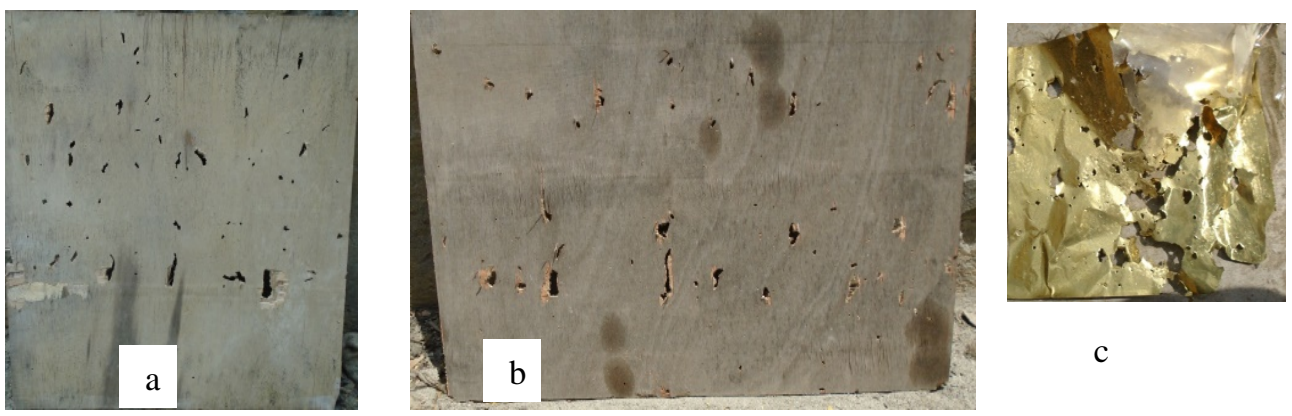

C

Figure 27: $(a, b)$ Plywood witness sheets (c) Timing probe placed below the shell base

Table 5: Measured mass and size of the recovered fragments and comparison with simulation results

\begin{tabular}{lccc}
\hline Fragment Mass (g) & \multicolumn{2}{c}{ Experimental } & ANSYS AUTODYN \\
\cline { 2 - 4 } & Length (mm) & Width (mm) & Length (mm) \\
\hline $3.9 \pm 0.1$ & $29.8 \pm 0.7$ & $9.4 \pm 0.2$ & 46 \\
$3.69 \pm 0.1$ & $48 \pm 1.2$ & $6 \pm 0.1$ & 40.52 \\
$3.0 \pm 0.1$ & $37.8 \pm 0.9$ & $5.4 \pm 0.1$ & 31 \\
$1.5 \pm 0.05$ & $21.9 \pm 0.5$ & $6.7 \pm 0.1$ & 15.35 \\
$0.9 \pm 0.04$ & $10 \pm 0.2$ & $8 \pm 0.2$ & 11.94 \\
$0.9 \pm 0.04$ & $12.6 \pm 0.3$ & $4.5 \pm 0.1$ & 12 \\
$0.6 \pm 0.03$ & $10.5 \pm 0.2$ & $4.8 \pm 0.1$ & 14.7 \\
$0.3 \pm 0.02$ & $13.8 \pm 0.3$ & $5.4 \pm 0.1$ & 9.96 \\
$0.2 \pm 0.01$ & $7.3 \pm 0.2$ & $4.9 \pm 0.1$ & 8.8 \\
$0.4 \pm 0.02$ & $7.8 \pm 0.2$ & $4.2 \pm 0.1$ & 10.33 \\
$0.2 \pm 0.01$ & $7.6 \pm 0.2$ & $6 \pm 0.1$ & 8.21
\end{tabular}

Considering the shell geometry and assuming a symmetrical fragment distribution in radial direction, and as witnessed from the fiberglass and plywood sheets shown in Figs. 26 and 27, the total number of fragments are grouped into the following three categories.

1. Small $(<0.04 \mathrm{~g})$

2. Medium (0.04-0.4g)

3. Large $(0.41-6.5 \mathrm{~g})$

A comparison of the number of fragments and their mass distribution is presented in Fig. 28. Most of the fragments have masses less than $0.5 \mathrm{~g}$. The SPH simulation results shown in Fig. 28 provided a good agreement with the experimental findings. A few of the recovered fragments of masses ranging between $0.2-3.9 \mathrm{~g}$ are in fair agreement with the simulation results. 


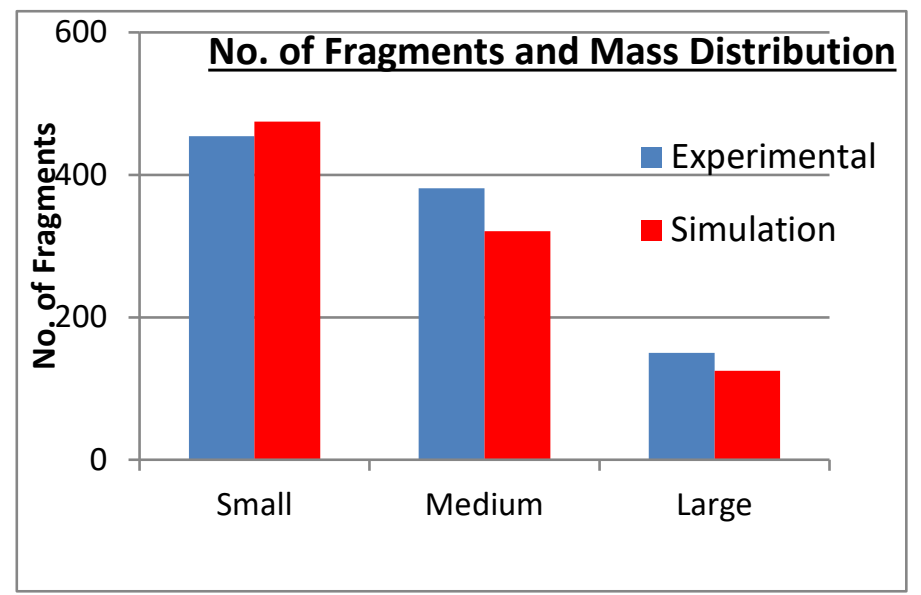

Figure 28: Number of fragments and their mass distribution for scaled shell

The peak overpressures (Ps) at $0.55,0.59,0.60,0.65,0.675$ and 0.760 meter distances are recorded. The pressure time history for experimental and simulated data at four of the above stated distances are shown in Fig. 29. Peak overpressure values of $44.2 \mathrm{psi}$ (304.7kPa) at $0.550 \mathrm{~m}$ and $23.38 \mathrm{psi}(161.2 \mathrm{kPa})$ at $0.675 \mathrm{~m}$ are measured. The corresponding time of arrival (Ta) is $0.505 \mathrm{~ms}$ and $0.733 \mathrm{~ms}$ respectively. Incident impulse of 3.3 and 1.8 psi-ms are computed corresponding to these peak overpressure values.

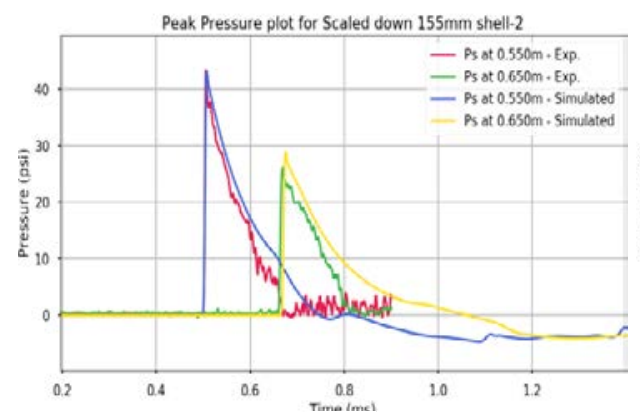

a

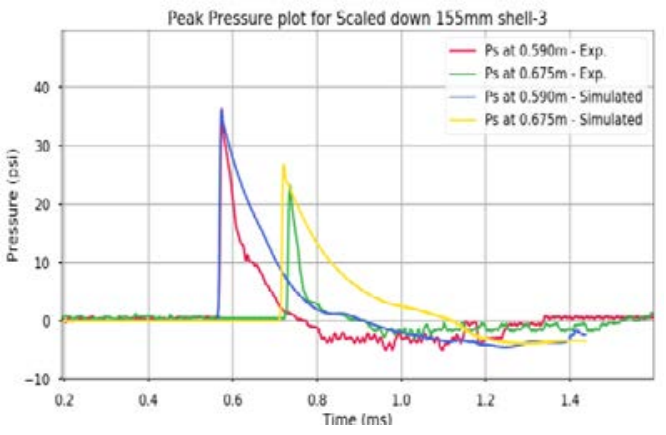

b

Figure 29: Experimental and simulated peak incident pressure plots at (a) $0.55 \mathrm{~m}$ \& $0.65 m$ (b) $0.59 m$ \& $0.675 m$

A summary of the experimental and simulated results is presented in Table 6. A good agreement between simulated and experimental results for the blast parameters is obtained for the scaled down model of $155 \mathrm{~mm}$ artillery shell. Therefore, one can utilize the simulation techniques to predict the blast and fragmentation effects of such munitions and hence minimize the cost and time consumption on full scale testing. 
Table 6: Summary of the experimental \& simulation Pressure -time values

\begin{tabular}{lllll}
\hline Distance & \multicolumn{2}{c}{ Experimental Results } & \multicolumn{2}{c}{ Simulation Results } \\
\hline $\mathbf{R}(\mathbf{m m})$ & $\mathbf{T a}(\mathbf{m s})$ & $\mathbf{P}_{\mathbf{s}}(\mathbf{p s i})$ & $\mathbf{T a}(\mathbf{m s})$ & $\mathbf{P}_{\mathbf{s}}(\mathbf{p s i})$ \\
\hline 550 & 0.505 & $44.2 \pm 1.1$ & 0.507 & 43.08 \\
590 & 0.573 & $36.54 \pm 0.9$ & 0.57 & 36.22 \\
600 & 0.603 & $35.5 \pm 0.9$ & 0.59 & 34.87 \\
650 & 0.668 & $26.5 \pm 0.6$ & 0.675 & 28.85 \\
675 & 0.733 & $23.38 \pm 0.5$ & 0.720 & 26.43 \\
760 & 0.882 & $16.79 \pm 0.4$ & 0.887 & 18.94 \\
\hline
\end{tabular}

\section{CONCLUSION}

Blast and fragmentation of the geometrically scaled-down model of a standard $155 \mathrm{~mm}$ artillery shell is investigated experimentally and numerically. Simple experimental approaches are employed to measure fragments' velocity, mass, and spatial distribution. Fragments having masses ranging from tens of milligrams to a few grams are produced with velocities ranging from 960 to $1555 \mathrm{~m} / \mathrm{s}$. The central part of the casing has more contribution among higher velocity fragments due to higher $\mathrm{C} / \mathrm{M}$ ratio as compared to the rear portion of the shell. Peak overpressures of $44.2 \mathrm{psi}(304.7 \mathrm{kPa})$ and $23.38 \mathrm{psi}(161.2 \mathrm{kPa})$ are recorded at $0.55 \mathrm{~m}$ and $0.675 \mathrm{~m}$ from the shell center. The numerical simulation of fragmentation is performed using Smoothed Particles Hydrodynamics (SPH) solver. The SPH simulations reasonably well reproduced fragments mass distribution and velocities. A coupled Euler-ALE (Arbitrary Lagrangian-Eulerian) approach is used to simulate the shell blast propagation in surrounding air. Good agreement has been observed for blast wave parameters determined using coupled ALE-Euler approach with experimental results. The investigation would help to develop protective configurations for protection of infrastructure and invaluable lives against the damaging effects of blast and fragmentation.

\section{ACKNOWLEDGMENT}

The authors are grateful and acknowledge the support of Dr. Naveeda, Mr. Mursaleen, Mr. S. Kazim Hussain, M. Ashraf and their team during the experimental work.

\section{REFERENCES}

[1] Kong, X., et al., A numerical investigation on explosive fragmentation of metal casing using Smoothed Particle Hydrodynamic method. Materials \& Design, 2013. 51: p. 729741.

[2] Ahmed, K., et al., Lightweight protective configurations against blast and fragments impact: Experimental and numerical studies. AIP Advances, 2020. 10(9): p. 095221. 
[3] Mott, N.F., Fragmentation of shell cases. Proceedings of the Royal Society of London. Series A. Mathematical and physical sciences, 1947. 189(1018): p. 300-308.

[4] Gurney, R.W., The initial velocities of fragments from bombs, shell and grenades. 1943, Army Ballistic Research Lab Aberdeen Proving Ground Md.

[5] Zecevic, B., et al. Influencing parameters on HE projectiles with natural fragmentation. in International Conference on New Trends in Research of Energetic Materials. 2006.

[6] Huang, G.-y., W. Li, and S.-s. Feng, Axial distribution of Fragment Velocities from cylindrical casing under explosive loading. International Journal of Impact Engineering, 2015. 76: p. 20-27.

[7] Prytz, A.K. and G. Odegardstuen, Fragmentation of $155 \mathrm{~mm}$ artillery grenade, simulations and experiment. 25th Int. J. Ballistics, September, 2011. 12: p. e22.

[8] Abdalla, M.A. Fragmentation Analysis of OG-7 Warhead Using AUTODYN SPH Solver. in Advanced Materials Research. 2012: Trans Tech Publ.

[9] Marriott, C., et al. Computer Modeling of Small Fragmenting Warhead in 3D. in 16th International Symposium on Ballistics, San Francisco, USA. 1996.

[10] Anderson JR, C.E., W.W. Predebon, and R.R. Karpp, Computational modeling of explosive-filled cylinders. International Journal of Engineering Science, 1985. 23(12): p. 1317-1330.

[11] Ma, T., et al., Fragment spatial distribution of prismatic casing under internal explosive loading. Defence Technology, 2019.

[12] Gold, V.M., Fragmentation model for large L/D (Length over Diameter) explosive fragmentation warheads. Defence technology, 2017. 13(4): p. 300-309.

[13] Arnold, W. and E. Rottenkolber, Fragment mass distribution of metal cased explosive charges. International journal of impact engineering, 2008. 35(12): p. 1393-1398.

[14] Nyström, U. and K. Gylltoft, Numerical studies of the combined effects of blast and fragment loading. International Journal of Impact Engineering, 2009. 36(8): p. 995-1005.

[15] Rasico, J., C. Newman, and M.R. Jensen, MODELING FRAGMENTATION OF A 155MM ARTILLERY SHELL IED IN A BURIED MINE BLAST EVENT. 2016.

[16] Jing, Q. and T. Zhou, Study of Grooved Warhead Structure on Performance of Warhead Fragment Distribution Pattern. International Journal of Multiphysics, 2018. 12(1).

[17] Ugrčić, M., Numerical simulation of the fragmentation process of high explosive projectiles. Scientific Technical Review, 2013. 63(2): p. 47-57.

[18] Cullis, I., et al., Numerical simulation of the natural fragmentation of explosively loaded thick walled cylinders. Defence Technology, 2014. 10(2): p. 198-210.

[19] Moxnes, J.F., et al., Experimental and numerical study of the fragmentation of expanding warhead casings by using different numerical codes and solution techniques. Defence technology, 2014. 10(2): p. 161-176. 
[20] An, X., et al., Fragment Velocity Characteristics of Warheads with a Hollow Core under Asymmetrical Initiation. Propellants, Explosives, Pyrotechnics, 2019. 44(8): p. 10491058.

[21] Tanapornraweekit, G. and W. Kulsirikasem, FEM Simulation of HE blast-fragmentation warhead and the calculation of lethal range. International Journal of Mechanical and Mechatronics Engineering, 2012. 6(6): p. 1070-1074.

[22] Lozano, E., Design and analysis of a personnel blast shield for different explosives applications. 2016, Colorado School of Mines. Arthur Lakes Library.

[23] Ahmed, K. and A.Q. Malik, Experimental studies on blast mitigation capabilities of conventional dry aqueous foam. AIP Advances, 2020. 10(6): p. 065130.

[24]ANSYS Inc., U., Century Dynamics. Release 14.0 documentation for ANSYS AUTODYN. 2011.

[25]Lee, E., H. Hornig, and J. Kury, Adiabatic expansion of high explosive detonation products, UCRL-50422. California: University of California, 1968.

[26] Meyers, M.A., Dynamic behavior of materials. 1994: John wiley \& sons.

[27] Johnson, G.R.a.C., W.H. A Constitutive Model and Data for Metals Subjected to Large Strains, High Strain Rates, and High Temperatures. in Proceedings 7th International Symposium on Ballistics. 1983. Hague.

[28] Johnson, G.R. and T.J. Holmquist. An improved computational constitutive model for brittle materials. in AIP Conference Proceedings. 1994: American Institute of Physics.

[29]van der Voort, M., E. Baker, and C. Collet, FRAGMENTATION FROM DETONATIONS AND LESS VIOLENT MUNITION RESPONSES. 2019.

[30] Li, Q., L. Lu, and T. Cai, Numerical investigations of trajectory characteristics of a highspeed water-entry projectile. AIP Advances, 2020. 10(9): p. 095107.

[31] Yeo, J.-S. and J. Szmelter, A method for predicting natural fragmentation of warheads. Journal of Battlefield Technology, 2003. 6(2): p. 11. 
